\title{
Using dual language picturebooks with children in an after school club
}

\author{
Nicola Daly \\ University of Waikato \\ Dorea Kleker and Kathy Short

\section{University of Arizona}

Dual language picturebooks use more than one language in the text of the book. There is increasing literature showing the potential of such books to support language learning, and recent studies explore their use in classrooms to raise awareness of multilingualism. This article describes the ways in which dual language picturebooks were used in an after school club of 8-11 year olds in a Latinx neighbourhood in Arizona. Over a six week period an inquiry cycle was used as a curricular framework for exploring dual language picturebooks featuring both familiar and unfamiliar languages for the children. Findings showed the importance of providing time for connection with the books, followed by demonstrations or readings of the picturebooks, and the importance of invitations for the children to explore ideas from the picturebooks. The article provides guidelines for using dual language picturebooks in classrooms, and ends with a provocation suggesting that bilingual picturebooks are not necessarily only for bilingual children.

Keywords: dual language picturebooks, bilingual picturebooks, inquiry cycle, after school club

\section{Introduction}

Dual language picturebooks use more than one language to tell a story. There are several types of dual language picturebooks: Interlingual picturebooks use one dominant language with occasional words and phrases from a second language; bilingual picturebooks tell the story fully in both languages within a book; and dual or multi version picturebooks have two (or more) separate versions of the same picturebook with the same design and illustrations but each in a different language. There has been some research exploring the layout of picturebooks which feature more than one language from the perspective of language hierarchies and hegemonies (Daly, 2017, 2019), and there is a growing body of literature exploring the power of picturebooks for language teaching (Bland, 2013; Bland \& Lutge, 2014).

Our research builds on previous research about the use of bilingual picturebooks in classrooms. Naqvi et al. (2013) explored children's responses to bilingual picturebooks read by community members in Canadian Kindergarten classes, while Sneddon (2009) engaged immigrant children in making bilingual picturebooks with their parents. Most recently Zaidi (2020) examined the effects of dual language picturebooks in classrooms of 10- to 12-year-old students. In these studies, the findings are linked to the role of these books in developing language awareness and in changing language attitudes towards multilingualism. This article explores the potential of dual language picturebooks for 
encouraging children's inquiries into language and culture, including engagements with books containing unfamiliar languages.

\section{Research methods}

After ethical approval was received, data was collected in an after school-club held regularly in a Latinx neighbourhood in Arizona, USA. The club met for 90 minutes one day a week in the school library. Over a six-week period we observed the children interacting with dual language picturebooks featuring English and a range of second languages, from languages with which they were familiar (Spanish) to languages with which they were unfamiliar (Te Reo Māori). We documented children's responses to the picturebooks using fieldnotes, audio recordings of discussions, children's journal entries, and photos of artefacts.

This article focuses on four students for whom pseudonyms have been assigned: Tina was an eight-year-old who lived in an English dominant home but used Spanish with her grandparents; Antonio was a nine-year-old who spoke both Spanish and English at home; Cassandra was nine years of age and spoke English at home with some Spanish; Safita was a 10-year-old from an English dominant home but her mother and extended family spoke Spanish.

Interlingual, bilingual and dual version picturebooks were chosen for each of the six sessions from the substantial global children's literature collection at the Worlds of Words Center based at the University of Arizona. In the first week, picturebooks featuring English and languages from around the world were used to introduce the children to the idea that books can contain more than one language. We decided to use Spanish-English picturebooks in weeks two and three, as this was a combination of languages familiar to all of the participants in their everyday lives. In weeks four and five we used picturebooks featuring English and Te Reo Māori, an indigenous New Zealand language with which the children had no familiarity, but was familiar to one of the researchers, and in the final week we used a collection of picturebooks featuring Indigenous American Indian languages, thus linking to the indigenous language of weeks four and five.

\section{Inquiry cycle}

Each of the six after school sessions was planned around an inquiry cycle framework (Short, 2009) around the focus and set of picturebooks (approximately 30-40) chosen for each session. In each inquiry cycle there were opportunities for the children to connect with the picturebooks; demonstrations by researchers on different aspects of the books; and invitations for children to engage in experiences related to the books. For example, the inquiry cycle in week two involved browsing picturebooks in Spanish/English at the start of the session, followed by a read-aloud of an interlingual picturebook featuring English and Spanish, I Love Saturdays y domingos (Ada, 2004), as a demonstration about translanguaging within dialogue. Children were then invited to draw a map of places in their communities where they hear multiple languages.

The components of this inquiry cycle provide a framework for the instructional strategies that encouraged children's explorations of language and culture through dual language picturebooks.

\section{Connection}

At the start of each after school session, 30 to 40 picturebooks related to our focus were laid out on the tables for children to browse as they entered the library, along with Post- 
it notes to write comments on books or graffiti boards to jot quick responses. This browsing provided a time for children to build knowledge, interest, and experiences from which to connect in the session.

Children engaged with the picturebooks in different ways. Antonio casually flipped through the pages, looking at several books by carefully studying illustrations; Tina approached each browsing looking for "sad" books; Safita settled in with books that caught her eye, often choosing to read these in their entirety, ignoring everyone else around her. When it came time to share the books with their classmates, connections between children and books became obvious: Cassandra liked My Heart Fills with Happiness (Smith, 2018) because it was happy and eagerly read her favourite page aloud; Tina liked Dabu, the Baby Dugong (Solomon, 2003) because it was sad; Safita offered a summary of her book, Naupaka (Beamer, 2008), which reminded Cassandra of the storylines common to princess movies.

\section{Demonstration}

The use of dual language picturebooks as a demonstration is prevalent in research on these books in classrooms, such as Naqvi et al., (2013) and Zaidi (2020) where adults read bilingual books to children. In our study, we explored demonstrations of both interlingual and bilingual picturebooks. The goal was for children to develop a repertoire of strategies for working out meaning for themselves in these books, both in familiar and unfamiliar languages.

In week two, Dorea read I Love Saturdays y domingos (Ada, 2004) and demonstrated how to use illustrations to support the understanding of unfamiliar vocabulary by repeating the Spanish words clearly and slowly and pointing to the illustration when children asked questions or expressed confusion during the read aloud. In week four Nicola read The Kuia and the Spider (Grace, 1982) featuring English text with some Māori words and phrases. Nicola asked children to guess the meaning of four Māori loanwords in the predominantly English text before she read the whole book aloud. She laid out numbered artifacts and children wrote their guess for the meaning of each Māori word on a piece of paper. As she read the book, children were encouraged to change or confirm their guesses and so paid close attention to the reading. During her read-aloud, Nicola provided demonstrations of aspects of the text and illustrations they could use as context clues for meaning. For example, she read, "They took kits to the garden and got kumara," and then repeated "they got kumara" pointing to the illustration. Safita said excitedly, "I was right about two of them."

In weeks three and five, we focused on bilingual picturebooks featuring English and Spanish (week three) and English and Māori (week five). The demonstrations in these weeks involved the researchers reading the two languages in the texts and observing the children's responses. In week three Kathy and Nicola read My Colors, My World/Mis colores, mi mundo (Gonzalez, 2007) with Nicola reading the English text and Kathy reading the Spanish text. While Spanish was a familiar language for children, English was their dominant language. We read the text in the order the languages were presented in the book, English first and then Spanish. Once this was done, we read the book again, this time in Spanish first and English second. We did this in order to see how the children responded to language order when reading a bilingual picturebook. Contrary to our expectations, our field notes indicated that children appeared less engaged with Spanish (less familiar language) when it was second than when it was read first. Safita later said that it was because she knew some Spanish so liked to listen to Spanish first to see how 
much she understood when the English was then read. In a later session, Nicola read a bilingual picturebook, The Marae Visit (Beyer \& Wellington, 2019), reading English first and then Māori before going back to read the first four pages with Māori first and English second. When she asked children whether the order felt any different with Māori first, only Antonio had an answer, "It felt like I was in New Zealand," indicating his feeling of immersion into the culture. Our field notes showed that children were less engaged when Māori was read first, perhaps because the language was unfamiliar to them, so they were not able to test themselves as Safita had done with Spanish.

\section{Invitations}

Each week, the final part of our inquiry cycle was an invitation to support both guided explorations (planned by the researchers) and personal inquiries (developed by children). For example, in week one, children browsed dual language picturebooks in multiple languages, followed by an invitation to place Post-it notes on a world map to label the languages children had heard about. This experience led to personal inquiries by children about what it means to 'know' a language, an inquiry they pursued over several weeks. Another invitation involved children creating body maps, colouring in the outline of a body to indicate where different languages were in their bodies. For example, Safita put Italian in her hands because she had learned Italian terms while learning to play the piano, and Tina put an American flag on her head because, she explained, this is where she memorised languages, but her body was all Mexican and so had a Mexican flag.

\section{Suggestions for using dual language picturebooks in the classroom}

Based on our experiences of using dual language picturebooks featuring English along with other languages that ranged from the familiar to the unfamiliar, we offer the following suggestions:

- Although we think it is a good idea to include familiar languages in explorations of bilingual picturebooks, we saw evidence of children also gaining insight by exploring picturebooks featuring languages of which they had no previous knowledge.

- Neither teachers nor children need to know all of the languages in the bilingual picturebooks which they explore. YouTube clips and community members can be used to support explorations of unfamiliar languages.

- When introducing children to bilingual picturebooks our study showed the value of providing time for children to browse the picturebooks first. This browsing offers opportunities for connections which open the possibility of exploration and inquiry.

- Giving children opportunities for sharing picturebooks from their browsing allows for connections to be made, ideas to be shared, and classmates and teachers to build on those ideas.

- Read alouds of bilingual picturebooks offer opportunities for children to learn about the context clues available in the illustrations and text to understand unfamiliar languages. 
- Teachers can alternate the order that they read languages in bilingual picturebooks, knowing that students may respond well to a less familiar language being read first; but if the less familiar language is completely unknown, it may be better second.

- Open-ended invitations and questions allow children to build and create their own inquiries. Teachers need to be careful not to dominate these discussions, but to work and think alongside children.

- When teachers work alongside children as they complete invitations, they become co-learners and gain insight into the development of ideas and inquiries for children.

\section{Conclusion}

Our study of children's interactions with different types of dual language picturebooks in an after school club has afforded us a window into the possibilities for these books within inquiry cycles in classrooms. We observed that children who have exposure to English and Spanish in their everyday lives not only respond well to Spanish-English picturebooks; they also engaged with picturebooks featuring languages with which they had no familiarity including Te Reo Māori and American Indian languages. Our research adds to a growing body of work exploring how dual language picturebooks can be used in educational settings by contributing an emphasis on an inquiry cycle as a curricular framework and the use of books featuring both familiar and unfamiliar languages.

\section{Are bilingual picturebooks for bilingual children?}

We end with a provocation around the question of the audience for bilingual picturebooks. It is easy to assume that bilingual picturebooks are for bilingual children who use the languages featured in the book, but our findings show the rich possibilities of bilingual picturebooks for children who may only know one of the languages featured in the book. Indeed, if we think about it, children who know and use more than one language in their everyday lives are already aware that different languages exist, provide different lenses on the world, and can be used in different ways. We suggest that bilingual picturebooks may be most powerful for children who do not know both languages featured in the book. When introduced to such books in an inquiry cycle, children have the opportunity to predict, try out new sounds and ways of writing, and extend their understanding of how language is defined and used.

\section{Acknowledgements}

The authors wish to acknowledge the participants in this research, and also Fulbright New Zealand and the University of Arizona who supported Nicola's time based at the Worlds of Words Center (wowlit.org).

\section{References}

Bland, J. (2013). Children's literature and learner empowerment children and teenagers in English language education. Bloomsbury Academic.

Bland, J., \& Lütge, C. (Eds.) (2014). Children's literature in second language education. Bloomsbury Academic. 
Daly, N. (2017). The linguistic landscape of English-Spanish dual language picturebooks. Journal of Multilingual and Multicultural Development.

https://doi.org/10.1080/01434632.2017.1410163

Daly, N. (2019). The Linguistic Landscape of Multilingual Picturebooks. Linguistic Landscape. An International Journal, 5(3), 281-301.

Naqvi, R., McKeogh, A., Thorne, K. J., \& Pfitscher, C. (2013). Dual-language books as an emergent literacy resource: Culturally and linguistically responsive teaching and learning. Journal of Early Childhood Literacy, 13(4), 501-528.

Short, K. (2009). Curriculum as inquiry. In S. Carber \& S. Davidson, (Eds.), International perspectives on inquiry learning (p. 11-26). John Catt.

Sneddon, R. (2009). Bilingual book-biliterate children: Learning to read through dual language books. Trentham Books.

Zaidi, R. (2020). Dual-Language books: Enhancing engagement and language awareness. Journal of Literacy Research. 52(3), 269-292.

\section{Children's books cited}

Ada, A.F. (2004). I love Saturdays y domingos (E. Savadier, Illus.). Aladdin.

Beamer, N. (2008). Naupaka (‥ Loebel-Fried, Illus.). Bishop Museum.

Beyer, R., \& Wellington, L. (2019). The marae visit (N. S. Robinson, Illus.). Duck Creek.

Gonzalez, M. C. (2007). My colors, my world.Mis colores, mi mundo. Children's Book Press.

Grace, P. (1982). The kuia and the spider (R. Kahukiwa, Illus.). Penguin.

Solomon, S. (2003). Dabu the baby dugong (D. Nona, Illus.). Magabala.

Smith, M. G. (2018). My heart fills with happiness (J. Flett, Illus.). Orca.

Nicola Daly is a sociolinguist and Associate Professor in the Division of Education at the University of Waikato, New Zealand where she teaches courses in children's literature. Her research focus is multilingual picturebooks and she was a Fulbright New Zealand Scholar in 2019/2020.

Email: nicola.daly@waikato.ac.nz

ORCiD: https://orcid.org/0000-0003-3548-0043 
Dorea Kleker is an early childhood teacher, educator and lecturer at the University of Arizona. Working with students and teachers across a wide variety of educational contexts in both the U.S. and Latin America, her work focuses on global and multicultural children's literature, literacy and play to develop intercultural understanding and the use of literature to actively engage children as inquirers across all content areas.

Email: dkleker@arizona.edu

ORCiD: https://orcid.org/0000-0002-4551-2945

Kathy G. Short is a professor and endowed chair of global children's literature in the College of Education at the University of Arizona, USA, and is Director of Worlds of Words: Center of Global Literacies and Literatures (wowlit.org). She has co-authored and coedited many books and articles, including Critical Content Analysis of Visual Images in Literature for Young People, Critical Content Analysis of Children's and Young Adult Literature, and Teaching Globally: Reading the World through Literature. She was President of the National Council of Teachers of English and the US Board of Books for Young People.

Email: shortk@arizona.edu

ORCiD: https://orcid.org/0000-0002-9431-366X 